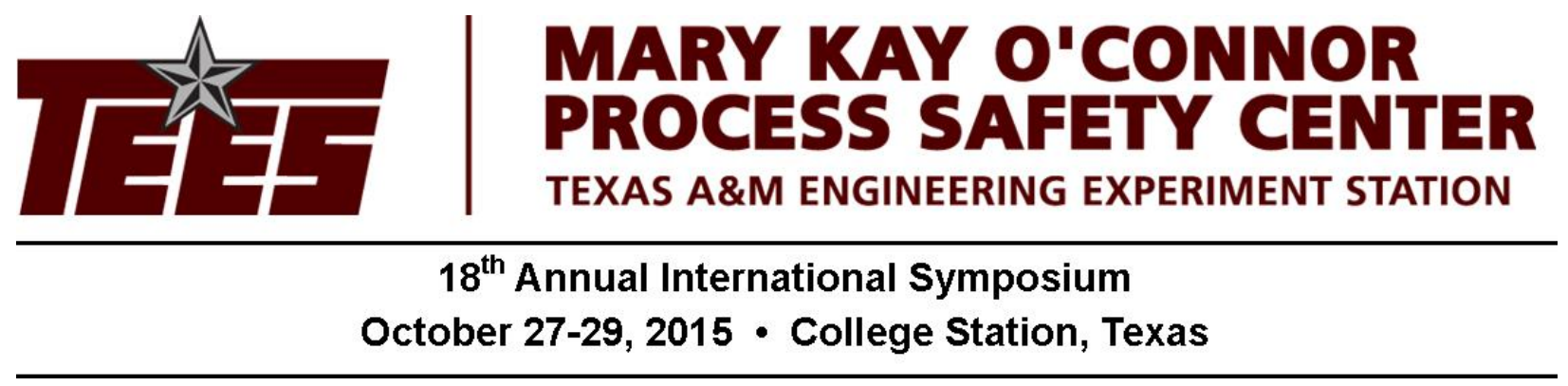

\title{
Pattern Recognition Techniques Implementation on Data from In-Line Inspection (ILI)
}

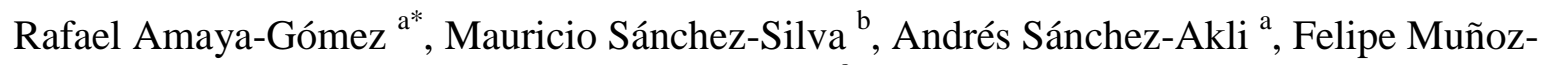 \\ Giraldo $^{a}$ \\ ${ }^{\mathrm{a}}$ Chemical Engineering Department, ${ }^{\mathrm{b}}$ Civil \& Environmental Department \\ Universidad de los Andes \\ Cra 1 No 18A- 12, Bogotá, Colombia. \\ *r.amaya29@uniandes.edu.co
}

\begin{abstract}
Onshore pipeline failure caused by corrosion represents about $16 \%$ of the overall number of incidents during the period from 2004 to 2011 according to databases such as CONCAWE and PHMSA. In-Line Inspection (ILI) is one of the available inspection techniques used to determine overall pipeline status, highlighted because it establishes a clear perspective of inner and outer condition of the pipe against the failure modes and wall thickness. Furthermore, it supports measures to prevent risk based on standards such as ASMEB31G or API579-1/ASME FFS-1. However, this approximation could represent a conservative assessment of the pipeline status, taking into account the uncertainty associated with ILI inspection tools such as MFL and UT. Several researches have been conducted to analyze available inspection techniques attempting to reduce noise generated by their inspection tools, and determine procedures in order to establish correct metal loss detection, excelling pattern recognition analysis and reliability concepts. Therefore this work seeks to transform a set of data obtained from two ILI runs, into useful information to support decision making in risk analysis based on pattern recognition techniques and reliability concepts, in order to obtain base failure frequencies for prior analysis from individual and grouped flaws. Moreover, growth corrosion and remaining life models supported on the standards mentioned above were evaluated using a pressure failure criteria. As a result it was obtained that the failure probability of the grouped flaws increases $10 \%$ in comparison with the corresponding flaws evaluated individually.
\end{abstract}

\section{Introduction}

Onshore pipeline for hydrocarbon transportation is the safest mean to supply energy demands worldwide. It is highlighted due to its low accidental frequency and small amount of related reported incidents with affected population [1]. Likewise, it represents the mean of transportation most used with a 71\% in comparison with other means (e.g. ships and barges with 22\%) [2]. Even though different tools to failure prevention are available, accidental events are still 
happening as it can be evidenced in databases such as CONCAWE and PHMSA. One hazard identified in these databases is associated with corrosion, which represents $18 \%$ and $13 \%$ of the reported cases between 2004 to 2011 in PHMSA [3] and CONCAWE [4], respectively.

One of the processes that address this hazard is pipeline integrity evaluation, which covers concepts of failure prevention, inspection-repair, among others [5]. This process implements non-destructive inspection techniques to inspect material defects without damaging the evaluated object. The Code of Federal Regulation for liquids and gases (CFR 192 and CFR 195, respectively) recognizes three acceptable methods to assess the mechanical integrity of a pipeline: i) In-Line Inspection, ii) hydrostatic tests and iii) direct assessment [6]. This last one is very useful for unpiggable systems, i.e. pipelines where a PIG (Pipeline Inspection Gauge) tool cannot be implemented. In-Line Inspection analysis (developed in guidance with NACE RP0102-2002 standard) is highlighted because it establishes a clear perspective of the inner and outer condition of the pipe against the failure type and the wall thickness. Moreover, it is the only inspection technique which offers a total coverage of the pipe [7], by implementing tools such as MFL (Magnetic Flux Leakage) or UT (Ultrasound) to determine the presence of corrosion and material loss.

Based on information from those tools, pipeline integrity evaluation can be obtained by implementing different standards such as NACE SP0169 (Control of External corrosion on underground or submerged Metallic piping system) [8], API 1160 (Managing System Integrity for Hazardous Liquid Pipelines) [9], API 579-1/ASME FFS-1 (Fitness for Service) [10], ASMEB31G (Manual for determining the remaining strength of corroded pipelines) [11] or DNV RP-F-101 (Recommended practices for corrode pipelines) [12]. However, some of these standards correspond to a conservative assessment of the corroded pipeline -as it can be shown in- given the noise associated with the analysis tools and by the fact that most of these standards use a deterministic rather than a probabilistic approximation [13, 14, 15]. For that reason, several researches have been conducted, in order to take advantage of the available information obtained, and establish a correct classification of the flaws or improve the metal loss detection on the pipe. One of the excelling tools is pattern recognition is the Support Vector Machines and Neural Networks, which has been used for example in leaking detection [16, 17, 18], for automatic flaw detection [19] or for the detection of wall thinning by the use of ultrasonic signals [20].

This work seeks to implement pattern recognition techniques to transform a set of available ILI runs, taking into account the uncertainty associated with the inspection tools, into useful information in order to support decision making. For the learning of the pattern recognition technique, defects grouping criteria from the standards API 579-1/ASME FFS-1 and ASMEB31G were took into consideration. Moreover, since the corrosion hazard is a time dependent phenomenon, it was developed a growth corrosion model to determine the failure probability and the remaining life of the evaluated pipeline.

This paper is organized as follows: Section 2 contains the inspection accuracies of the ILI tools and the level assessments of the corrosion flaws (Level 0, Level 1, Level 2 and Level 3) from the standard ASMEB31G. Section 3 presents a review of growth corrosion models; Section 4 contains the proposed model, which includes: the growth corrosion model, failure probability, 
and remaining life assessments; case of study is presented in Section 5, and the results analysis in Section 6. Finally, Section 7 contains concluding remarks.

\section{Inspection accuracies and ASMEB31G level assessments}

The provided information in an ILI analysis basically consists on geometric information of the encountered flaws on the pipeline (e.g. the length, depth, width, the circumferential position, among others) that is used in mechanical integrity analysis. Two important aspects to consider are the obtained flaw specifications (detection and identification probability) and the confidence level of data (Table 1) [7].

Cracks have to be found and ideally dimensioned, before they reach a certain critical size of the material. In Fracture Mechanics, this size is the boundary between having a subcritical crack and a rapid crack growth which is independent of the external load, conducted by the energy stored in the front of the crack tip [21]. One of the available tools to assess corrosion defects corresponds to the usage of Level 0,1, 2 and 3 of ASMEB31G, which corresponds with the benchmark for the pipeline evaluation [22].

Table 1. In-Line Inspection corrosion tools comparison

\begin{tabular}{|c|c|c|}
\hline & MFL & UT \\
\hline 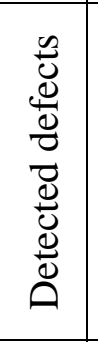 & $\begin{array}{l}\text { It is primarily sensitive to the depth and the } \\
\text { circumferential extent of an anomaly [6]. MFL is } \\
\text { stress sensitive, recent attention has been focused on } \\
\text { using these tools to detect mechanical damage in the } \\
\text { pipe caused by rocks, landslide or third party } \\
\text { interference [23]. }\end{array}$ & $\begin{array}{l}\text { Metal loss on either the inside or } \\
\text { outside surface is detected by a } \\
\text { change in the time of flight of the } \\
\text { signal. Likewise, it identifies } \\
\text { other types of flaws on the } \\
\text { pipeline as cracks or material } \\
\text { separation [6]. }\end{array}$ \\
\hline t & $\begin{array}{l}\text { Long narrow areas of metal loss or axial cracks } \\
\text { cannot be detected because the flux field is parallel to } \\
\text { the length of the anomaly and the flux is not pushed } \\
\text { outside of the wall thickness [6]. }\end{array}$ & $\begin{array}{l}\text { This tool does not detect cracks } \\
\text { with a length shorter than } 30 \mathrm{~mm} \text {. } \\
\text { Moreover, must have a minimum } \\
\text { depth of } 2 \mathrm{~mm} \text { [24]. }\end{array}$ \\
\hline 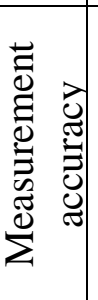 & $\begin{array}{l}\text { With a } 80 \% \text { of confidence, there are two types of } \\
\text { tools [25]: } \\
\text { - Industrial standard (high resolution): } \pm 10 \% \text { of } \\
\text { the wall thickness detection. } \\
\text { Extra high resolution: } \pm 5 \% \text { of the wall thickness } \\
\text { detection. }\end{array}$ & $\begin{array}{l}\text { With a } 90 \% \text { of confidence [25]: } \\
\text { Industrial standard: } \pm 4 \mathrm{~mm}\end{array}$ \\
\hline
\end{tabular}

This standard has the purpose to provide guidance in the evaluation of metal loss in pressurized pipeline systems, for the pipelines included in the transport code of the ASMEB31G. It is applicable for the assessment of metal loss due to internal and external corrosion, at any depth respect to the wall thickness. However, it is not applicable for selective corrosion or to evaluate the metal loss on accessories different from pipeline elbows. The user could choose between Level $0,1,2$ or 3 depending on the amount and quality of the available data, which the assessment are going to develop, likewise, their level of refinement should be taken into account [11]. 
Just to mention, Level 0 evaluation implements permissible length tables, while a Level 1 evaluation use simple measurements as the maximum defect depth and the axial extent of the metal loss. This level is used to determine which flaws have a higher priority over all the identified. A Level 2 evaluation incorporates a greater level of detail than a Level 1 evaluation in order to produce a more accurate estimate of the failure pressure. It typically relies on detailed measurements of the corroded surface profile, accounting for the actual distribution of metal loss. An evaluation of Level 3 is a detailed analysis of a specific failure with user-defined methodology, generally finite elements. The latter assessment is beyond the scope of this work. The Level 0, Level 1 and Level 2 methodology determine if a flaw is permissible or not. It is worth to be mentioned, that ASMEB31G defines a flaw as permissible, if its failure stress is equal or higher than the hoop stress at the operating pressure multiplied by a safety factor (no shorter than 1.25). Moreover, it is recommended to use the ratio between the design pressure and MAOP (Maximum allowable operating pressure) for this safety factor [11].

\section{Review of existing corrosion growth models}

As it was mentioned above, corrosion is a time dependent hazard so it is necessary to develop a model for growth corrosion considering the available information from the ILI runs. Several growth corrosion models are used in the oil and gas industry, e.g. the Waard model, Casandra model, Norsok model, Hydrocor model, KSC model, and the SwRI [26]; however, most of the models are deterministic and dependent of the fluid properties. For that reason, in this work the Hasan and the Amirat models were implemented. The Hasan model develops a probabilistic approach and the Amirat model implement a power law fitting of historical data.

\subsection{Hasan model:}

Hasan et al. (2012) made a review of different mathematical models to determine growth corrosion, highlighting: the Waard-Milliams equation, Waard-Lotz equation and the SwRI (South West Research Institute) model. The first two equations were found to provide comparatively higher corrosion rates with lower correlation with data. Therefore, the third equation, developed by SwRI, is considered for the rate estimation [Eq.1] [27].

$$
\begin{array}{rl}
\frac{d a}{d t}=k * C_{1} * & 0,0254 \\
& *\left[8.7+9.86 e^{-3}\left(O_{2}\right)-1.48 e^{-7}\left(O_{2}\right)^{2} 1.31(p H)\right. \\
& +4.93 e^{-2}\left(p C O_{2}\right)\left(p_{H_{2} S}\right)-4.82 e^{-5}\left(p_{C O_{2}}\right)\left(O_{2}\right)-2.37 e^{-3}\left(p_{H_{2} S}\right)\left(O_{2}\right) \\
& \left.-1.11 e^{-3}\left(O_{2}\right)(p H)\right]
\end{array}
$$

Where:

- $\mathrm{O}_{2}$, is oxygen concentration [ppm].

- $k$, is a modeling error.

- $\quad p_{\mathrm{H}_{2} \mathrm{~S}}$, is the partial pressure of the hydrogen sulfide in the mix [bar].

- $p_{\mathrm{CO}_{2}}$, is the partial pressure of carbon dioxide in the mix [bar].

- $C_{1}$, is the inhibitor correction factor, given by: $C_{1}=1-\exp \left[-A \frac{L}{L_{0}}\right]$

\subsection{Amirat model:}


The second model was the proposed by Amirat et al. (2006), for uniform corrosion. It uses a power law regression to represent the metal loss of the wall thickness given an exposure time. If $k$ and $n$ are constants, the general form of the corrosion power law is written as [Eq.2], where $t_{c}$ is the thickness of the corroded layer (in $\mathrm{mm}$ ) and $T$ is the elapsed time. To obtain the unknown constants fitting from historical corrosion data is necessary [28].

$$
t_{c}=k T^{n}
$$

\section{Pattern recognition-based corrosion model}

The proposed model was developed taking into account the available information by the ILI runs, the inspection tools measurement accuracy, and the review of the growth corrosion models. This model uses a probabilistic approximation for the corrosion growth and a pressure failure criterion to determine the failure probability not only for individual defects, but also for groups of defects (obtained by pattern recognition techniques). Furthermore, the remaining life of the pipeline is evaluated by the implementation of the standard API 579-1/ASME FFS-1.

\subsection{Probabilistic model:}

The probabilistic model to determine the growth corrosion rate was developed base on the available data from the two ILI runs. Changes in the depth defects between the two ILI runs were determined, using an uncertainty of $5 \%$ of the implemented inspection tool to locate the corrosion defects (MFL with extra high resolution).

Once the depth changes were obtained from the corrosion flaws, it was assumed that they were independent between each other in order to perform Goodness for Fit Tests, and could determine the distribution that better fits to the available data. The tests implemented were: KolmogorovSmirnov, Anderson-Darling and Chi-Square. The mathematical aspects of each of the tests could be review in [29]

\subsection{Failure criterion:}

Once the growth corrosion rate is determined, it is possible to establish if the system fulfill the sufficient requirements for its correct operation, or if a failure will occur at any point of their life cycle. In engineering design the distinction between the modes of failure are typically reached by categories of design criteria, which are commonly named as limit states. As is stated in [30], the common base for different reliability levels is the introduction of the limit state function, which represents a mathematical definition of an event failure in mechanical terms. With the aim to obtain this function, it is necessary to determine the maximum allowable loads of the structure (usually named as a resistance $R$ ) and the loads that the structure would be subjected (named as solicitation $S$ ). The reason why this general approach was applied is because the resistance and the solicitation usually depend on many parameters [Eq. 3], which corresponds to a reliability problem with high dimension [30].

$$
g\left(x_{1}, x_{2}, \ldots\right)=R\left(x_{1}, x_{2}, \ldots\right)-S\left(x_{1}, x_{2}, \ldots\right)
$$

It is worth to be mentioned that for positive values of the limit state function the evaluate structure would be in a safe state, while in negative values the evaluated structure would be in a failure state. In case that the structure is at the boundary between the two cases mention above, it 
would be on a failure surface. Based on the mentioned above, it was implemented a pressure limit state function with the operating pressure as solicitation and the burst pressure (where the pipe wall bulges outward and reach a point of instability [31]) as the resistance. Four models were used to determine the burst pressure: ASMEB31G (2009) [11], DNV RP-F101 (2010) [12], CSA 662-07 (2007) [32] and Netto et al. (2005) [33].

\subsection{Grouping criterion}

Most of the researches work done in corrosion assessment has focused on learning about isolated defects; however, the pressure of an interacting defect will be lower than in the isolated case because it will interact with their neighbor's defects. Some standards such as DNV RP-F101, BS 7910, CSA Z184, API579-1/ASME FFS-1, and ASMEB31G provide guidance for grouping and assessing metal loss defects that may interact [34, 35]. The ASMEB31G criterion establishes that two flaws interact between each other if the distance among them (circumferentially or axially) is shorter than three times the wall thickness of the evaluated pipeline [11]. The API579-1/ASME FFS-1 grouping criterion begins with initial measurements of the maximum longitudinal and circumferential extents of the flaw, and then it is develop an imaginary box with twice the flaw size determined before. If another flaw exists within that box, the flaws are grouped and the imaginary box should adjust its size to include the addition area [10]. Figure 1 shows an example of this last grouping criterion. It is worth to be mentioned, that the implementation of the defect clock position (available from the ILI runs) on the pipeline is necessary for any of these approximations. The clock position is defined as the relative distance of an object described using an analogy of a 12-hour clock [36].
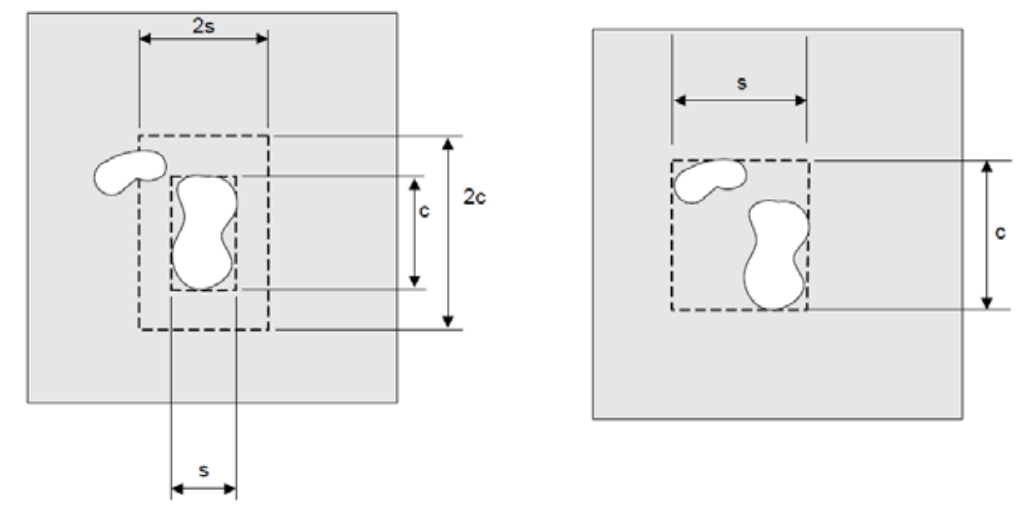

Figure 1. API 579-1/ASME FFS-1 grouping criterion [10]

As is well known, pattern recognition is classified as supervised or unsupervised learning. In the first case, it is assumed that a set of training data was available and the classifier was designed by exploiting this a priori known information and to design the classification region [37]. In the other side, training data of known class labels are not available. In this type of problem, it is given a set of a feature vector and the goal is to unravel the underlying similarities and join the similar vectors together [37]. Concerning the grouping defect criterion, pattern recognition techniques could be used to cluster the defects not only by a supervised learning, taking into account one of the standards approximation criterion explained above -as a training set-, but also with an unsupervised learning using the distance between them. 
Some of the most important supervised learning classifiers are linear classifiers (e.g. Rosenblatt Perceptron and Fisher or Gaussian), linear or logistic regressions, support vector machines, regression trees, and k-nearest neighbors. In unsupervised learning classifiers, the most important classifiers are PCA (Principal Component Analysis), hierarchical or fuzzy clustering, and Kmeans [38].

\subsection{Failure probability}

The resistance and the solicitation explained above have a probabilistic -rather than a deterministic- approximation, taking into account the uncertainty of the mechanical parameters they are based on. For that reason, the failure probability is obtained integrating the join probability distribution on the failure region. Assuming that all the involved random variables in the system are given by $\vec{X}=\left(x_{1}, x_{2}, \ldots, x_{n}\right)$ and the limit state function is $g(\vec{X})=0$, it follows that the failure probability is calculated as [Eq. 4] [39], where $f_{\vec{X}}(\vec{x})$ denotes the variables vector join probability distribution. It is worth to be mentioned, that failure probability integration has an analytic solution only in special cases, hence it is necessary to implement alternative methods such as numerical integration, Monte Carlo simulation or approximated methods such as FORM (First Order Reliability Method) [39].

$$
P_{f}=P[g(\vec{X}) \leq 0]=\int \cdots{ }_{g(\vec{X}) \leq 0} \int f_{\vec{X}}(\vec{x}) d \vec{x}
$$

Just to mention, the general definition of the reliability index (Hasofer and Lind), corresponds to the minimum distance from the origin in a normalized space, to the limit state function. The point where the distance is shorter is the most probable failure point or the design point [39]. FORM is an iterative procedure used to determine the reliability index for a nonlinear (as well as linear) limit state function. It is an analytical approximation in which the reliability index is interpreted as the minimum distance from the origin to the limit state surface in a standardized normal space and the design point. The construction and the relevant aspects of FORM could be review in [39, 40, 41].

\subsection{Remaining life}

Another important tool to support decision making in pipelines, is the remaining life analysis. Corrosion is a time dependent process, therefore, if their damage cannot be addressed to mitigate it, the possible consequences of the future flaws should be evaluated in order to ensure that the defects do not reach its critical measure, before to the next inspection. Some standards that assess the remaining life are API 579-1/ASME FFS-1 and API 570 (Piping Inspector Program) [42].

The API 579-1/ASME FFS-1 fitness-for-service assessment procedures cover both the present integrity of the component given a current state of damage and the projected remaining life. The assessment techniques involved in this standard includes flaws evaluation for general and localized corrosion, widespread and localized pitting, blisters and hydrogen damage, crack-like flaws including environmental cracking, dents and gouges, and remaining life assessment procedures for components operating in the creep range [10].

For this standard, the remaining life of a component could be determined by two approaches: the maximum allowable working pressure (MAWP) and the maxim fill height (MFH) [10]. In the first case, it begins with the calculation of the minimum allowable thickness $\left(t_{\min }\right)$, the average 
thickness at time of the inspection $\left(t_{a m}\right)$, and the estimated corrosion rate $\left(C_{\text {rate }}\right)$ [Eq. 5]. The calculation of these parameters is shown in [43].

$$
R_{L}=\frac{t_{a m}-K t_{\text {min }}}{C_{\text {rate }}}
$$

Besides of the implementation of standards for assessing the pipeline remaining life, there are several deterioration models. Structural deterioration, generally is defined as any change on a material or geometric property, which affects their structural capacity. Assuming that a structural component has an initial capacity, it can be determined the structural deterioration based on the initial state and the cumulative deterioration in a certain time. According with the evaluated capacity, there are two fundamentals thresholds: 1 ) the system intervention is necessary and a preventive maintenance should be employed to obtain a new initial capacity. 2) The component should be replaced due to the excessive mechanical deterioration [44].

\section{Case of study}

The case of study of this work is based on two ILI runs (ILI Run-1 and ILI Run-2) of a pipeline named as Pipeline- $A$ with a timespan of two years between each inspection. This pipeline is made of carbon steel with an alloy of grade API5LX52. Table 2 shows a summary of the evaluated system.

Table 2. Pipeline-A summary parameters

\begin{tabular}{|c|c|c|}
\hline Parameter & Value & Units \\
\hline Outer diameter & 273.1 & $\mathrm{~mm}$ \\
\hline Nominal diameter & 10 & $\mathrm{in}$ \\
\hline $\begin{array}{c}\text { Pipeline length } \\
\text { Pressure) }\end{array}$ & 44 & $\mathrm{~km}$ \\
\hline $\begin{array}{c}\text { MAOP (Maximum Allowable Operating } \\
\text { Strength) }\end{array}$ & 1500 & $\mathrm{psig}$ \\
\hline $\begin{array}{c}\text { SMYS (Specified Minimum Yield } \\
\text { Strength) }\end{array}$ & 52000 & $\mathrm{psig}$ \\
\hline $\begin{array}{c}\text { Average wall thickness } \\
\text { Operating temperature range }\end{array}$ & 60000 & $\mathrm{psig}$ \\
\hline Operating velocity range & $30.4-$ & ${ }^{\circ} \mathrm{C}$ \\
\hline
\end{tabular}

An MFL tool was used to perform the ILI inspection, however, its accuracy is unknown. Hence it was develop a review of the available tools of the company which conducts the inspection, shown in Table 3. 
Table 3. MFL tools of ROSEN [45]

\begin{tabular}{|c|c|c|c|c|}
\hline Tool & $\begin{array}{c}\text { Circumferen } \\
\text { tial } \\
\text { localization } \\
\text { accuracy }\end{array}$ & $\begin{array}{c}\text { Depth } \\
\text { accuracy[m } \\
\text { m] }\end{array}$ & $\begin{array}{c}\text { Length accuracy } \\
\text { (Level of } \\
\text { confidence) [mm] }\end{array}$ & $\begin{array}{c}\text { Width accuracy } \\
\text { (Level of } \\
\text { confidence) [mm] }\end{array}$ \\
\hline $\begin{array}{c}\text { RoCombo MFL-A/UT } \\
\text { Service }\end{array}$ & $8 \mathrm{~mm}$ & 0.06 & $6(95 \%)$ & $8(95 \%)$ \\
\hline $\begin{array}{c}\text { ROCORR MFL-A } \\
\text { SERVICE }\end{array}$ & $5 \%$ & $0.1 \mathrm{t}$ & $15(80 \%)$ & $15(80 \%)$ \\
\hline $\begin{array}{c}\text { ROCOMBO MFL-C/XT } \\
\text { SERVICE }\end{array}$ & $\mathrm{NR} *$ & $0.15 \mathrm{t}$ & $15(80 \%)$ & $15(80 \%)$ \\
\hline $\begin{array}{c}\text { ROCORR MFL-A BIDI } \\
\text { SERVICE }\end{array}$ & $5 \%$ & $0.1 \mathrm{t}$ & $15(80 \%)$ & $15(80 \%)$ \\
\hline $\begin{array}{c}\text { ROCOMBO MFL-A/XT } \\
\text { SERVICE }\end{array}$ & $\mathrm{NR}$ & $0.1 \mathrm{t}$ & $15(80 \%)$ & $15(80 \%)$ \\
\hline $\begin{array}{c}\text { ROCORR MFL-C } \\
\text { SERVICE }\end{array}$ & $5 \%$ & $0.15 \mathrm{t}$ & $15(80 \%)$ & $15(80 \%)$ \\
\hline
\end{tabular}

*NR: No reporting parameter for this tool

\section{Analysis}

A first approach to make a processing data is to classify each defect by their morphology. One of the industrial classification criteria corresponds to the one reported by the Pipeline Operators Forum (POF) (Table 4). This approximation is based on the defects measurements: length $(L)$, width $(W)$ and a parameter $A$ which corresponds to the wall thickness (if it is greater than 10 $\mathrm{mm}$ ) or $10 \mathrm{~mm}$ otherwise [36].

Table 4. Metal loss anomaly classification [36]

\begin{tabular}{|l|l|}
\hline \multicolumn{1}{|c|}{$\begin{array}{c}\text { Anomaly dimension } \\
\text { class }\end{array}$} & \multicolumn{1}{|c|}{ Definition } \\
\hline General & $\{\mathrm{W}>=3 \mathrm{~A}\}$ y $\{\mathrm{L}>=3 \mathrm{~A}\}$ \\
\hline Pitting & $\begin{array}{l}\{1 \mathrm{~A}<=\mathrm{W}<6 \mathrm{~A}\} \quad, \quad\{1 \mathrm{~A}<=\mathrm{L}<6 \mathrm{~A}\} \quad \text { y } \\
\{0,5<\mathrm{L} / \mathrm{W}<2\}\end{array}$ \\
\hline Axial grooving & $\{1 \mathrm{~A}<=\mathrm{W}<3 \mathrm{~A}\}$ y $\{\mathrm{L} / \mathrm{W}>=2\}$ \\
\hline $\begin{array}{l}\text { Circumferential } \\
\text { grooving }\end{array}$ & $\{\mathrm{L} / \mathrm{W}<=0,5\}$ y $\{1 \mathrm{~A}<=\mathrm{L}<3 \mathrm{~A}\}$ \\
\hline Pinhole & $\{0<\mathrm{W}<1 \mathrm{~A}\}$ y $\{0<\mathrm{L}<1 \mathrm{~A}\}$ \\
\hline Axial slotting & $\{0<\mathrm{W}<1 \mathrm{~A}\}$ y $\{\mathrm{L}>1 \mathrm{~A}\}$ \\
\hline Circumferential slotting & $\{\mathrm{W}>1 \mathrm{~A}\}$ y $\{0<\mathrm{L}<1 \mathrm{~A}\}$ \\
\hline
\end{tabular}

Nevertheless, due to the uncertainty of the pipeline inspection tools for axial defects, the responsible vendor company performs field comparison in order to obtain a final classification of the reported flaws according to their morphology. This classification is included in the ILI available runs. Considering the mentioned above, it was developed a metal loss distribution of the evaluated pipeline with the reported morphology classification, for the inner and outer wall of the pipeline, for the both ILI runs (Figure 2). 

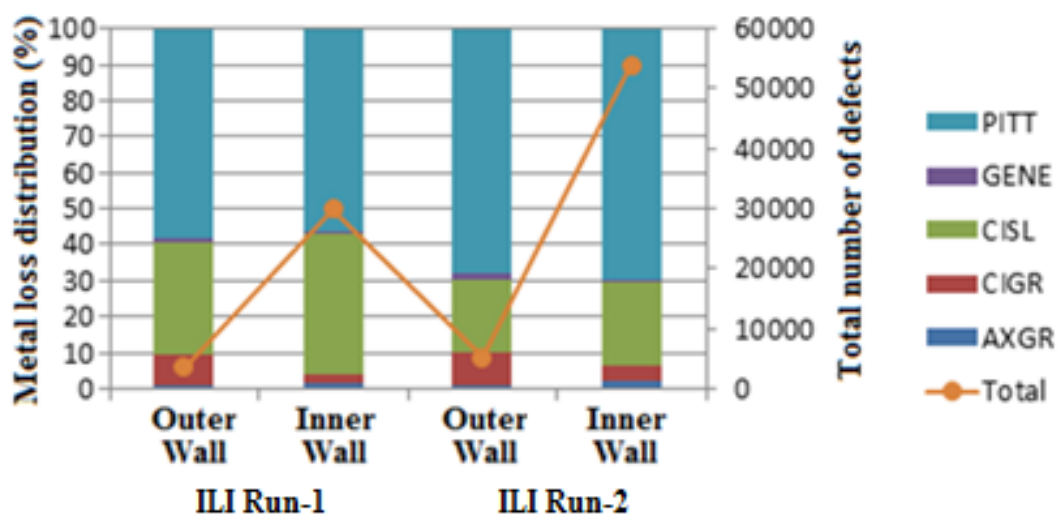

Figure 2. Failure distribution according to their morphology for inner and outer pipeline wall

Based on this distribution, it can be evidenced that: i) almost $50 \%$ of the defects are classified as pitting and the remaining are distributed mainly in circumferential slotting, and ii) the metal loss defects are focused in the inner wall. It is worth to be mentioned, that some of the metal loss anomaly classification from Table 4 are not reported in the ILI runs, as the pinhole case, which could correspond to the inspection tool accuracy restrictions, reported by the company vendor [46].

\subsection{ASMEB31G Evaluation}

As it was discussed above, it was developed a Level 0, Level 1 and Level 2 evaluation of the reported corrosion defects from the ILI runs. These evaluations were implemented with the data from the inner and outer wall of the pipeline, with the aim to identify non-permissible pipeline section over the pipeline abscissa. For that reason, it was determined the non-permissible pipeline section distribution for each evaluation level, in order to identify the most critical pipeline sections. Table 5 shows the results obtained for the sections with more than $5 \%$ of the non-permissible reported defects, in each ILI run.

It should be noted, that Level 2 evaluation is performed using the effective area method. It is a similar procedure as the Level 1 evaluation, but instead of implementing a parabolic approximation, it uses the real defect profile to assess the ratio of the metal loss areas [11]. However, the real defects profiles were not available in the ILI runs; therefore an approximation of the effective area was developed using the mean defect depth (available in the ILI runs). 
Table 5. Level 0,1 and 2 evaluation results of the selected segments

\begin{tabular}{|c|c|c|c|c|c|c|c|c|c|c|c|c|}
\hline \multirow{3}{*}{$\begin{array}{c}\text { Abscissa } \\
(\mathbf{k m})\end{array}$} & \multicolumn{4}{|c|}{ Level 0} & \multicolumn{4}{|c|}{ Level 1} & \multicolumn{4}{|c|}{ Level 2} \\
\hline & \multicolumn{2}{|c|}{ ILI Run-1 } & \multicolumn{2}{|c|}{ ILI Run-2 } & \multicolumn{2}{|c|}{ ILI Run-1 } & \multicolumn{2}{|c|}{ ILI Run-2 } & \multicolumn{2}{|c|}{ ILI Run-1 } & \multicolumn{2}{|c|}{ ILI Run-2 } \\
\hline & $\begin{array}{c}\text { Inner } \\
\text { wall } \\
(\%) \\
\end{array}$ & \begin{tabular}{|c|} 
Outer \\
wall \\
$(\%)$ \\
\end{tabular} & $\begin{array}{c}\text { Inner } \\
\text { wall } \\
(\%) \\
\end{array}$ & $\begin{array}{c}\text { Outer } \\
\text { wall } \\
(\%) \\
\end{array}$ & $\begin{array}{c}\text { Inner } \\
\text { wall } \\
(\%) \\
\end{array}$ & $\begin{array}{c}\text { Outer } \\
\text { wall } \\
(\%) \\
\end{array}$ & $\begin{array}{c}\text { Inner } \\
\text { wall } \\
(\%) \\
\end{array}$ & $\begin{array}{c}\text { Outer } \\
\text { wall } \\
(\%) \\
\end{array}$ & $\begin{array}{c}\text { Inner } \\
\text { wall } \\
(\%) \\
\end{array}$ & $\begin{array}{c}\text { Outer } \\
\text { wall } \\
(\%) \\
\end{array}$ & $\begin{array}{c}\text { Inner } \\
\text { wall } \\
(\%) \\
\end{array}$ & $\begin{array}{c}\text { Outer } \\
\text { wall } \\
(\%) \\
\end{array}$ \\
\hline 1 & 0.00 & 9.52 & 0.00 & 0.00 & 0.00 & 31.60 & 5.82 & 27.11 & 0.00 & 31.60 & 5.76 & 26.95 \\
\hline 2 & 0.00 & 0.00 & 0.00 & 3.57 & 11.54 & 23.11 & 10.58 & 27.41 & 7.84 & 23.11 & 10.47 & 27.25 \\
\hline 3 & 0.00 & 0.00 & 0.00 & 0.00 & 30.77 & 9.91 & 16.93 & 15.06 & 20.92 & 9.91 & 16.75 & 14.97 \\
\hline 4 & 0.00 & 0.00 & 0.00 & 0.00 & 31.73 & 18.40 & 32.28 & 15.96 & 21.57 & 18.40 & 31.94 & 15.87 \\
\hline 5 & 0.00 & 4.76 & 25.00 & 3.57 & 25.96 & 13.21 & 33.86 & 11.45 & 17.65 & 13.21 & 33.51 & 11.38 \\
\hline 9 & 0.00 & 19.05 & 0.00 & 7.14 & 0.00 & 0.94 & 0.00 & 0.00 & 0.00 & 0.94 & 0.00 & 0.00 \\
\hline 11 & 100.00 & 0.00 & 0.00 & 0.00 & 0.00 & 0.00 & 0.00 & 0.00 & 0.00 & 0.00 & 0.00 & 0.00 \\
\hline 12 & 0.00 & 4.76 & 0.00 & 10.71 & 0.00 & 0.00 & 0.00 & 0.60 & 0.00 & 0.00 & 0.00 & 0.90 \\
\hline 14 & 0.00 & 0.00 & 25.00 & 0.00 & 0.00 & 0.00 & 0.00 & 0.00 & 0.00 & 0.00 & 0.52 & 0.00 \\
\hline 28 & 0.00 & 4.76 & 25.00 & 7.14 & 0.00 & 0.47 & 0.00 & 0.30 & 0.00 & 0.00 & 0.52 & 0.30 \\
\hline 31 & 0.00 & 0.00 & 0.00 & 0.00 & 0.00 & 0.00 & 0.00 & 0.00 & 5.23 & 0.00 & 0.00 & 0.00 \\
\hline 34 & 0.00 & 4.76 & 0.00 & 10.71 & 0.00 & 0.47 & 0.00 & 0.60 & 0.00 & 0.47 & 0.00 & 0.60 \\
\hline 35 & 0.00 & 4.76 & 0.00 & 7.14 & 0.00 & 0.00 & 0.00 & 0.00 & 0.00 & 0.00 & 0.00 & 0.00 \\
\hline 43 & 0.00 & 14.29 & 25.00 & 17.86 & 0.00 & 0.94 & 0.53 & 0.60 & 3.92 & 0.47 & 0.52 & 0.60 \\
\hline 44 & 0.00 & 9.52 & 0.00 & 0.00 & 0.00 & 0.00 & 0.00 & 0.00 & 5.23 & 0.94 & 0.00 & 0.00 \\
\hline 45 & 0.00 & 9.52 & 0.00 & 14.29 & 0.00 & 0.00 & 0.00 & 0.60 & 0.00 & 0.00 & 0.00 & 0.60 \\
\hline
\end{tabular}

Note: The red color represents an increase of percentage from the ILI Run-1 and ILI Run-2 evaluations. The green color represents a decrease of percentage from the ILI Run-1 to the ILI Run-2 evaluation. The yellow color represents there were no changes in the percentage from the ILI Run-1 to the ILI Run-2 evaluation.

As it can be noted in Table 5, the Level 0 results from the ILI Run-1 (at the inner wall) shows that only the kilometer 11 obtained non-permissible metal losses, while at the outer wall, it was distributed along the pipeline abscissa, highlighting the segments from the $\mathrm{km} 5$ to 9, and $\mathrm{km} 43$ to 45 , which represents the $57.14 \%$ of the non-permissible segments. The results obtained between ILI Run-1 and ILI Run-2 were compared on the same evaluation level, obtaining that in ILI Run-2 ILI run does not occurs non-permissible defects in the inner wall at the kilometer 11,

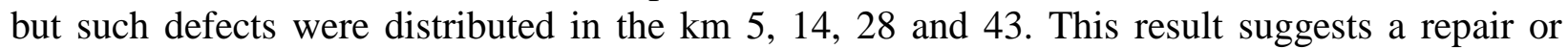
maintenance over that pipe section between ILI Run-1 and ILI Run-2. In relation to the outer

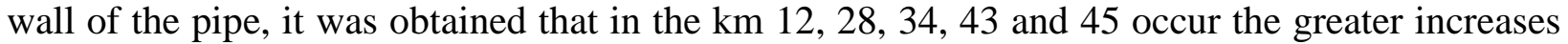
of the non-permissible defects in comparison to the ILI Run-1 reported data (the $\mathrm{km} 12$ and 34 segment show the greater increases with 5.95\%).

According to the results obtained from the Level 1 and Level 2 evaluations, there were not reported important non-permissible defects at the km 11 -nor km 45-, unlikely to the results reported in the Level 0 evaluation (with a mean of $74 \%$ from the total non-permissible defects in those segments). Suggesting that this last evaluation corresponds to a more conservative evaluation as is stated in [11]. For that reason, the selection of the segments was focused on the Level 1 and Level 2 evaluations. The selected pipeline segments were the $\mathrm{km} 1$ to 5, since they represents an average of the $94 \%$ of non-permissible defects in these evaluations. 
Finally, the total failure frequencies were obtained from each evaluation level (Table 6). These frequencies were calculated using the ratio of all the non-permissible defects over the total number of defects and the length of the evaluated pipeline. It is highlighted that the results from the Level 0 evaluation, presents an important change between the two ILI runs (6.85e-08 - 3.12e05 to $2.89 \mathrm{e}-06-2.62 \mathrm{e}-05)$.

The obtained failure frequencies were compared with the standard DNV RP-F101 -a recommended practice for corroded pipelines-, obtaining that the Level 0 results are classified with a high-normal safety class (because their frequencies are lower than 1e-05 and 1e-04), while the Level 1 and Level 2 are classified as a low safety class (their frequency is lower than 1e-03). DNV Safety Class High is used for sections of pipeline that are close to platforms, or in areas with frequent human activity. Safety Class Low can be considered, e.g. water injection pipelines [12].

Table 6. Total failure frequencies for each ASMEB31G evaluation level

\begin{tabular}{|c|c|c|c|}
\hline \multirow{2}{*}{$\begin{array}{c}\text { Evaluated } \\
\text { dataset }\end{array}$} & \multicolumn{3}{|c|}{ Failure frequency(event/km*year) } \\
\cline { 2 - 4 } & Level 0 & Level 1 & Level 2 \\
\hline $\begin{array}{c}\text { INT ILI Run- } \\
1\end{array}$ & $6.85 \mathrm{E}-08$ & $2.97 \mathrm{E}-04$ & $3.01 \mathrm{E}-04$ \\
\hline $\begin{array}{c}\text { EXT ILI Run- } \\
1\end{array}$ & $3.12 \mathrm{E}-05$ & $4.46 \mathrm{E}-04$ & $4.35 \mathrm{E}-04$ \\
\hline $\begin{array}{c}\text { INT ILI Run- } \\
2\end{array}$ & $2.89 \mathrm{E}-06$ & $4.07 \mathrm{E}-04$ & $4.07 \mathrm{E}-04$ \\
\hline $\begin{array}{c}\text { EXT ILI Run- } \\
2\end{array}$ & $2.62 \mathrm{E}-05$ & $6.52 \mathrm{E}-04$ & $6.52 \mathrm{E}-04$ \\
\hline
\end{tabular}

The deepest defects were located using the clock position and the abscissa of the pipeline, obtaining that the $\mathrm{km} 1, \mathrm{~km} \mathrm{5}, \mathrm{km} \mathrm{7,} \mathrm{km} \mathrm{9,} \mathrm{km} \mathrm{33}, \mathrm{km} 34$ and $\mathrm{km} \mathrm{43}$, present a depth greater than the $50 \%$ of the wall thickness (Figure 3). These defects are all located on the outer pipeline wall.

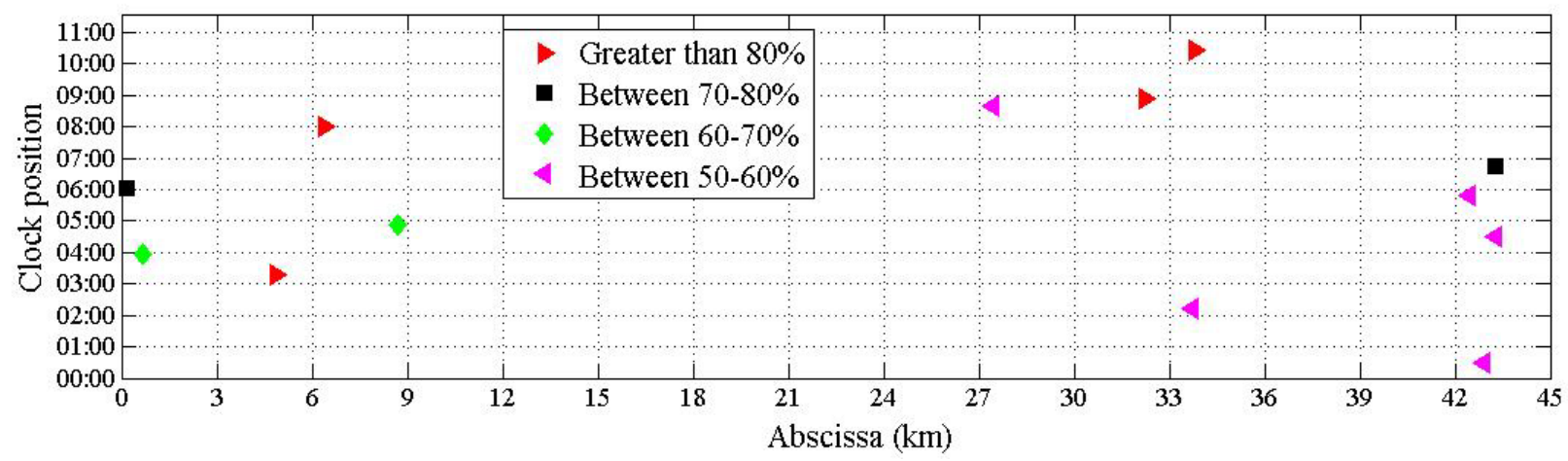

Figure 3. Corrosion defects with a depth greater than the $50 \%$ of the wall thickness.

The data processing was focused on the selected pipeline segments by the ASMEB31G evaluation (which determined the segments with higher number of non-permissible defects) and the localization of the deepest defects on the pipeline (which identifies the weakest segments). 
It was developed a comparison between the selected segments by their number of defects and some basic statistics of the maximum depth in those kilometers, shown in Table 7 . Based on the results obtained, it was identified that the $\mathrm{km} \mathrm{5,} 33$ and 43 represents the most critical segments because their average depth is greater. Besides, the $\mathrm{km} 5,7$ and 33 have greater depths in the outer wall (85\%); while the km 5, 7 and 43 in the inner wall.

Table 7. Results of number of defects and depth ranges of the selected sections

\begin{tabular}{|c|c|c|c|c|c|c|c|c|}
\hline \multirow{2}{*}{$\begin{array}{c}\text { Abscissa } \\
\text { (km) }\end{array}$} & $\begin{array}{c}\text { Inner } \\
\text { wall } \\
\text { (ILI } \\
\text { Run-1) }\end{array}$ & $\begin{array}{c}\text { Outer } \\
\text { wall } \\
\text { (ILI } \\
\text { Run-1) }\end{array}$ & $\begin{array}{c}\text { Inner } \\
\text { wall } \\
\text { (ILI } \\
\text { Run-2) }\end{array}$ & $\begin{array}{c}\text { Outer } \\
\text { wall } \\
\text { (ILI } \\
\text { Run-2) }\end{array}$ & $\begin{array}{c}\text { Anner wall } \\
\text { (ILI Run- } \\
\text { 1) }\end{array}$ & $\begin{array}{c}\text { Outer wall } \\
\text { (ILI Run-1) }\end{array}$ & $\begin{array}{c}\text { Inner wall } \\
\text { (ILI Run- } \\
\text { 2) }\end{array}$ & $\begin{array}{c}\text { Outer wall } \\
\text { (ILI Run- }\end{array}$ \\
\hline 1 & 0 & 87 & 17 & 116 & - & $16.52 / 10 / 74$ & $\begin{array}{c}10.59 \\
\text { 2) }\end{array}$ & $\begin{array}{c}12.20 \\
/ 10 / 30\end{array}$ \\
\hline 2 & 12 & 54 & 21 & 103 & $\begin{array}{c}11.25 \\
/ 10 / 20\end{array}$ & $13.35 / 10 / 46$ & $\begin{array}{c}10.52 \\
/ 10 / 15\end{array}$ & $\begin{array}{c}12.32 \\
/ 10 / 53\end{array}$ \\
\hline 3 & 34 & 22 & 35 & 56 & $\begin{array}{c}11.62 \\
/ 10 / 19\end{array}$ & $12.32 / 10 / 20$ & $\begin{array}{c}10.60 \\
/ 10 / 16\end{array}$ & $\begin{array}{c}10.73 \\
/ 10 / 15\end{array}$ \\
\hline 4 & 38 & 48 & 71 & 65 & $\begin{array}{c}12.18 \\
/ 10 / 18\end{array}$ & $14.52 / 10 / 23$ & $\begin{array}{c}10.93 \\
/ 10 / 22\end{array}$ & $\begin{array}{c}13.61 \\
/ 10 / 25\end{array}$ \\
\hline 5 & 32 & 33 & 73 & 74 & $\begin{array}{c}11.80 \\
/ 10 / 21\end{array}$ & $18.27 / 10 / 85$ & $\begin{array}{c}11.89 \\
/ 10 / 22\end{array}$ & $\begin{array}{c}13.03 \\
/ 10 / 36\end{array}$ \\
\hline 7 & 771 & 1 & 1259 & 0 & $\begin{array}{c}11.80 \\
/ 10 / 23\end{array}$ & $85 / 85 / 85$ & $\begin{array}{c}11.54 \\
/ 10 / 27\end{array}$ & - \\
\hline 9 & 707 & 265 & 2003 & 215 & $\begin{array}{c}11.71 \\
/ 10 / 19\end{array}$ & $19.29 / 10 / 69$ & $\begin{array}{c}11.19 \\
/ 10 / 26\end{array}$ & $\begin{array}{c}19.75 \\
/ 10 / 52\end{array}$ \\
\hline 33 & 348 & 9 & 899 & 4 & $\begin{array}{c}11.58 \\
/ 10 / 19\end{array}$ & $30 / 10 / 85$ & $\begin{array}{c}11.18 \\
/ 10 / 21\end{array}$ & $21 / 12 / 24$ \\
\hline 34 & 0 & 1829 & 456 & 2998 & - & $15.99 / 10 / 26$ & $\begin{array}{c}11.12 \\
/ 10 / 21\end{array}$ & $\begin{array}{c}14.37 \\
/ 10 / 60\end{array}$ \\
\hline 43 & 1305 & 180 & 1764 & 236 & $\begin{array}{c}11.92 \\
/ 10 / 31\end{array}$ & $20.35 / 10 / 58$ & $\begin{array}{c}11.63 \\
/ 10 / 39\end{array}$ & $\begin{array}{c}19.64 \\
/ 10 / 58\end{array}$ \\
\hline
\end{tabular}

\subsection{Growth corrosion model}

A comparison of the evaluated growth corrosion models was performed according to their required inputs available from the ILI runs, the external from the ILI runs, and the output of each model (Table 8).

Table 8. Growth corrosion models summary

\begin{tabular}{|c|c|c|c|}
\hline $\begin{array}{c}\text { Class of } \\
\text { parameters }\end{array}$ & Hasan (2012) & Amirat (2006) & Probabilistic model \\
\hline Input (ILI) & $d, t, \sigma_{u}, \sigma_{y}, l, L$ & $t$, year & $\Delta d$ (Depth change) \\
\hline External input & $P_{o p}$, fluid properties & $k, n$ (fit parameters) & Goodness for fit tests \\
\hline Output & $\begin{array}{c}\text { Corrosion rate } \\
{[\mathrm{mm} / \text { year] }}\end{array}$ & $\begin{array}{c}\text { Corroded wall thickness } \\
\left(t_{c}\right) \text { en } T\end{array}$ & $\begin{array}{c}\text { Corrosion delta per } \\
\text { year [mm] }\end{array}$ \\
\hline
\end{tabular}


Table 8 shows that the Hasan model requires the operating pressure and the fluid properties; which are not included in the available data from the ILI runs, and clearly they do not correspond to single values. Therefore, Hasan proposed to use probability density functions as the Lognormal for the fluid properties, and a Gumbel or maximum values distribution for the operation pressure [27]. On the other side, the Amirat model was fitted with the available two ILI runs, assuming that only two temporally spaces exists. The defects were split into two categories: 1) the defects that appeared in the ILI Run-2, but not in the corresponding on ILI Run-1 and, 2) the defects that appeared in both ILI runs.

Finally, for the probabilistic model was implemented the Goodness for Fit Tests, obtaining that the corrosion rate was fitted to 58 continuous distributions. One of the distributions that have a better behavior was the Gamma distribution, with a shape parameter of 1.318 and a scale parameter of 2.478. This result agrees with the reported in [47, 48, 49], associated with the metal loss evaluation by growth corrosion.

The three models explained above were evaluated over the time as it is shown in Figure 4. The results were divided into three regions: A safe zone, a plastic strain region and a structural damage region. These regions were determined considering that the average wall thickness of the evaluated pipeline is $6.35 \mathrm{~mm}$, and -as is mentioned in the DNV RP F-101 standard [12]- the plastic strain is reached when the defect depth reaches an $85 \%$ of the wall thickness. Moreover, with this figure an estimated remaining life of the pipeline can be obtained using the needed time to reach the plastic strain region, finding: Hasan model, 30 years; Probabilistic model, 40 years, and Amirat model 65 years.

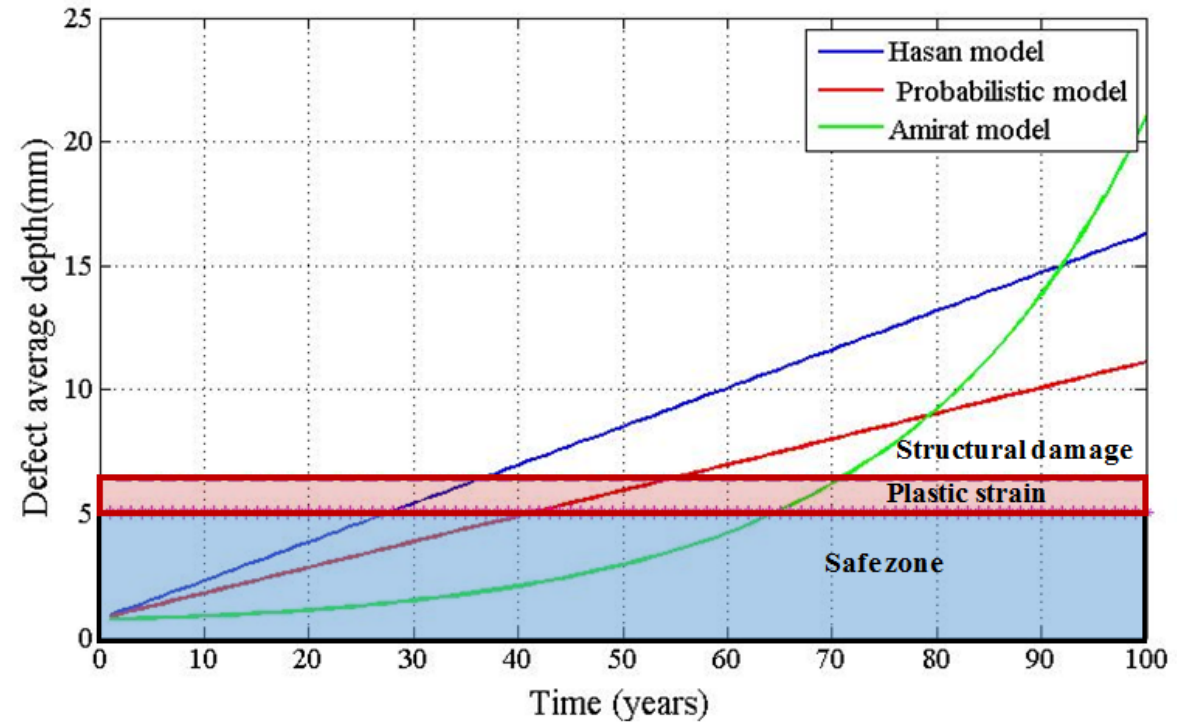

Figure 4. Results of the growth corrosion rate models.

Based on the information of Table 8 and the results obtained in Figure 4, the Hasan and the Amirat models were not taken into consideration. In first place, the Hasan model requires many unknown parameters of the fluid properties and the operating pressure, which would generate an important uncertainty in the final results. In the other hand, the Amirat model was not used because the available ILI runs are not sufficient to establish a correct trend between the 
implemented fit with the power law growth corrosion. Consequently, this work uses the last model associated with a probabilistic approximation (Gamma distribution).

\subsection{Grouping flaws}

The grouping criterion implemented was the proposed by ASMEB31G, instead of the discussed above from the API 579-1/ASME FFS-1, due to the uncertainty associated with the ILI inspection tool to determine the axial and circumferential measurements of each flaw [50]. The ASMEB31G criterion establishes that two flaws interact between each other if the distance among them (circumferentially or axially) is shorter than three times the wall thickness of the evaluated pipeline. To determine whether a defect could be classified as grouped, circumferences around every defect with radius of three times the wall thickness were implemented, obtaining a potential grouping region. On the evaluated region it was determined if there exists another defect besides the center. Once the grouping defects were formed, it was necessary to join the nearest defects to obtain the equivalent dimensions of the grouped flaws (Figure 5).

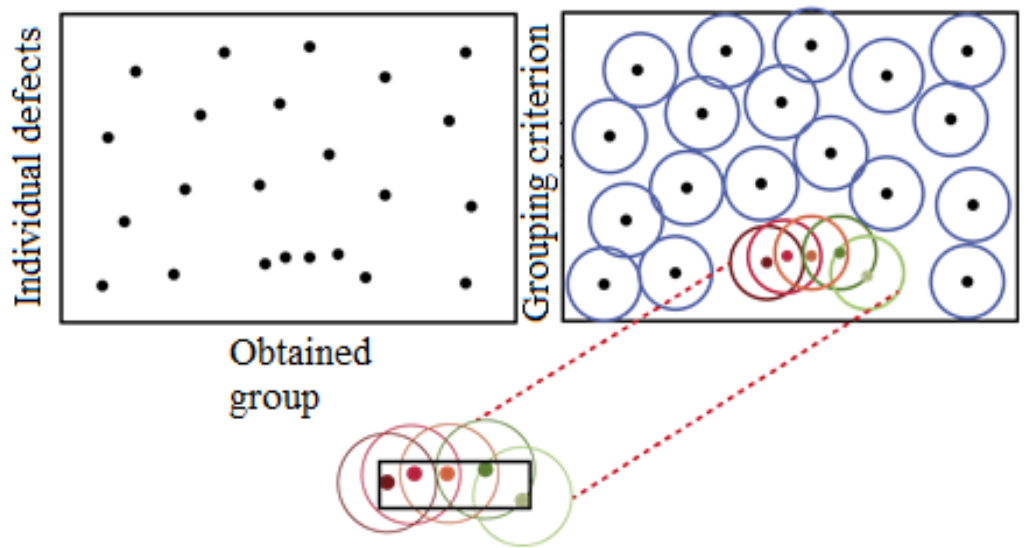

Figure 5. Grouping flaw criterion with final dimensions

This grouping criterion was applied on every corrosion defect in the ILI Run-1, obtaining 2268 groups. Moreover, it was evidenced that the defects groups are concentrated in the last half of the pipeline and in most of the cases they follow a circumferential grouping. This behavior suggests that the joins and welds along the pipeline may be the cause in most of the cases, taking into account that corrosion defects are often focus on a $200 \mathrm{~mm}$ distance from the welded joints [51].

In this work a supervised and an unsupervised pattern recognition techniques were implemented to assess the grouping of corrosion defects. In the supervised case, it was used the groups obtained with the grouping classification criterion established in ASMEB31G, as a training sample to perform the ILI Run-2 grouping classification. In the other case, it was used an unsupervised pattern recognition technique to group the defects by their location using the groupable defects.

\subsubsection{Supervised classification:}

Since this classification problem corresponds to a highly nonlinear problem and it has 2268 categories, procedures associated with a linear classifier cannot be implemented (or regression 
type). Therefore, methods such as the Fisher linear discriminant, support vector machine (SVM) and k-nearest neighbors should be tested to perform the classification.

Just to mention, the Fisher classifier has the purpose to find a hyperplane in which the projected data in that direction have a maximum separation between the evaluated categories. Moreover, this classifier is used to address The Curse of dimensionality, because it works in a reduced classifying space [52]. The support vector machine obtains a description that is capable to form a decision boundary around the domain of the training sample, with very little knowledge of the data that are outside of it. This is an approximation that uses a kernel map seeking the maximum separation between the categories, hence when it is mapped to the original space could separate the different categories [53]. Finally, the k-nearest neighbor's method begins with a new query which is used to determine the $\mathrm{k}$ nearest neighbors using a Euclidean distance. Subsequently, it is assigned the category corresponding to the majority of the sample of the k neighbors.

To evaluate the Fisher linear discriminant, the dimension of the sample was reduced by projecting the data in the direction where the distance between each of the categories is maximized. Reduced variables were obtained by projecting on the clock position direction. Once the data were projected on the reduced variable, linear classifiers obtaining an important classification error, since many classes are overlapped and a distinction between groups is not feasible. Therefore this approach was not taken into account.

The k-nearest neighbors (KNN) and SVM methods need certain parameters to perform their respective classification. The KNN method requires the number of neighbors in which the voting criterion is based on, in order to determine the category of the new queries, while the SVM requires the penalizing parameter of the constraints violation. To determine the best parameters to perform the classification, a Cross-Validation test was carried out for each technique. In this test different values of each parameter were evaluated against their mean squared error in order to select those who obtained the minimum error. In the case of the KNN classifier it was evaluated different kernels, while for the SVM classification a radial kernel was used.

From the results obtained in both Cross-Validation tests, it was determined that the classifier that should be used is the KNN classifier (with an inverse kernel and 4-nearest neighbors) instead of the SVM. This selection is due to the obtained classification mean squared error, which for the KNN was a fourth time shorter than for the SVM classifier. The results obtained with the SVM classifier could be caused by the constraints associated with the sample size [54].

\subsubsection{Unsupervised classification:}

This work implements K-Means, one of the most widely used procedures to perform an unsupervised analysis. K-Means is a procedure that defines $K$ centroids, which are called as prototypes or grouping centers. For each observation of the testing sample is calculated the distance to each centroid, hence, the observation is assigned to the cluster with the nearest distance to the centroid. Finally, the centroids are calculated again as a random process and the procedure is repeated until there are no changes [38].

The K-Means procedure was implemented on the ILI Run-2, in the free statistic software $R$ Project. The method used in this software was the Harigan \& Wong algorithm [55], which uses 
as input an $\mathrm{M} \times \mathrm{N}$ matrix ( $M$-observations of $N$-dimensions), and an initial matrix $K$ of $N$ dimensions with the preliminary clusters. This method seeks to obtain a partition of the sample in the $\mathrm{K}$ clusters, in which a local optimum in the square sum in each cluster is reached by moving observations from one cluster to another. In order to obtain the best classification possible, it was implemented a sensitivity analysis of the number of centroids against the within cluster sum of square distances for each cluster. From this result, it was found that the number of centroids should be 3806. There is no sense taking a larger number of centroids, which would be equivalent to a smaller sum square distance for each cluster, because the number of centroids would exceed the half of the initial grouping categories, ensuring that there will be one or more centroids with only one defect.

The supervised and the unsupervised classification techniques were used to obtain the equivalent grouping dimensions, as is shown in Figure 5, to perform a further evaluation of their failure probability and compare with the individual failure probability.

\subsection{Failure probability}

Given that the pressure failure criterion was selected to evaluate the growth corrosion, the limit state equation of ASMEB31G [11], DNV RP-F101 [12], CSA 662-07 [32] and Netto model [33] were implemented. These models calculate the burst pressure from the depth of the defects, the wall thickness, pipeline diameter, length of defects, and their stresses (yield and tensile).

To develop the FORM method it was necessary to assume that the wall thickness, the yield stress (SMYS) and the tensile stress (SMTS) were constant. This is not a strong assumption considering that $99.9 \%$ of the reported data from the ILI runs have a yield stress value of 359 $\mathrm{MPa}$, and $98.9 \%$ have a reported wall thickness of $6.35 \mathrm{~mm}$. Since the operating pressure was unknown, it was taken as a random variable with a Gumbel or maximum values distribution, as is proposed by Hasan [27]. It is worth to be mention, that this variable was adjusted with a mean shorter than the reported MAOP (Maximum Allowable Operating Pressure).

It was used the software $2 R$-Soft with its packages $2 R$ Data and $2 R R e l$. The first package was used to fit the data obtained in the cumulative growth corrosion model using at the beginning the reported defects in the ILI Run-2. In the second package the FORM method was developed based on the results from the first package and the assumptions mentioned above. However, the results obtained with this software could not be compared with the corresponding of Monte Carlo and the reliability index, because results after 32 years are not possible to be generated. Given the limitations found with FORM for the first case, it was not taken into account.

From the results obtained in Figure 6, it can be noted that the failure probability of the system changes significantly between each of the models evaluated. For example, the failure probability at 20 years using Monte Carlo simulation for each model is: ASMEB31G 60\%, Netto 10\%, DNV 70\% and CSA 20\%. These results suggest that the standards ASMEB31G and DNV RP-F101 approximation could be a little conservative in comparison to the Netto and CSA approximations. This agrees with the exposed by Teixeira et al. (2008) [13], where a comparison was performed between ASMEB31G approximation and the Netto model. 


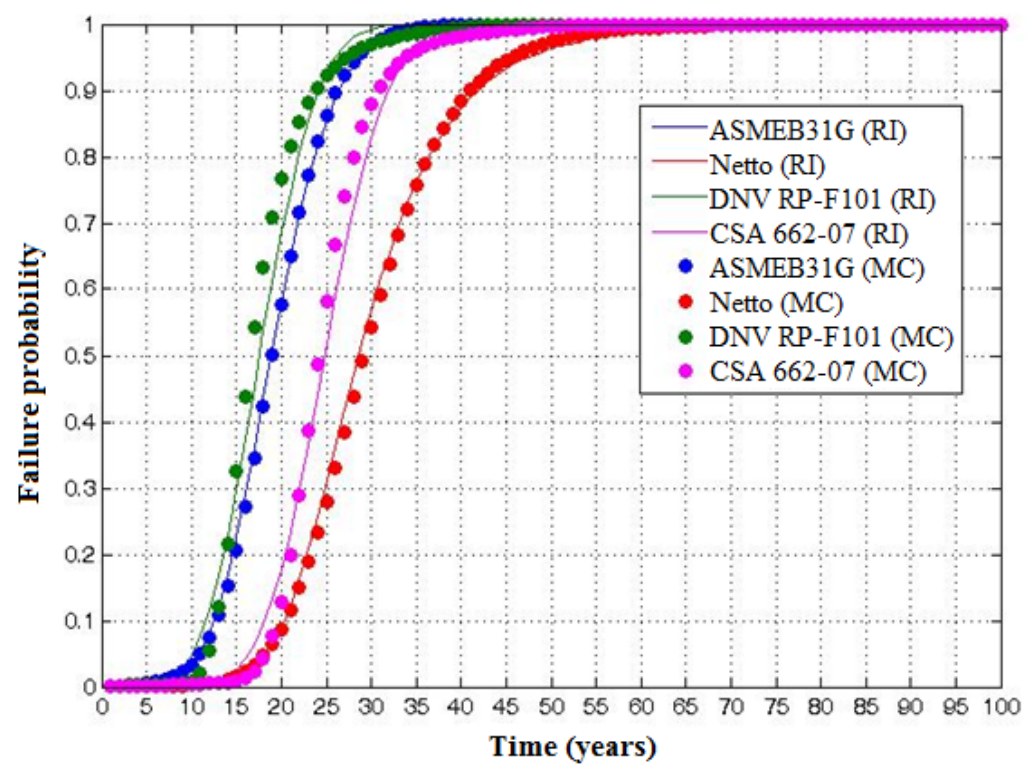

Figure 6. Failure probability results using Monte Carlo Simulation and the reliability index The results in Figure 6 corresponds to the failure probability for individual defects, regardless the possible groups it could be formed as it was mentioned before. Based on the parameters found by the Cross-validation method for the k-nearest neighbors and K-Means methods, the failure probability was determined for each of the evaluated models, for both of the pattern recognition techniques as is shown in Figure 7. However, given that the Monte Carlo results have a behavior very similar to the obtained by the reliability index, but the latter approximation has a computational time greatly lower, the only approach used for the grouping defects was the reliability index.

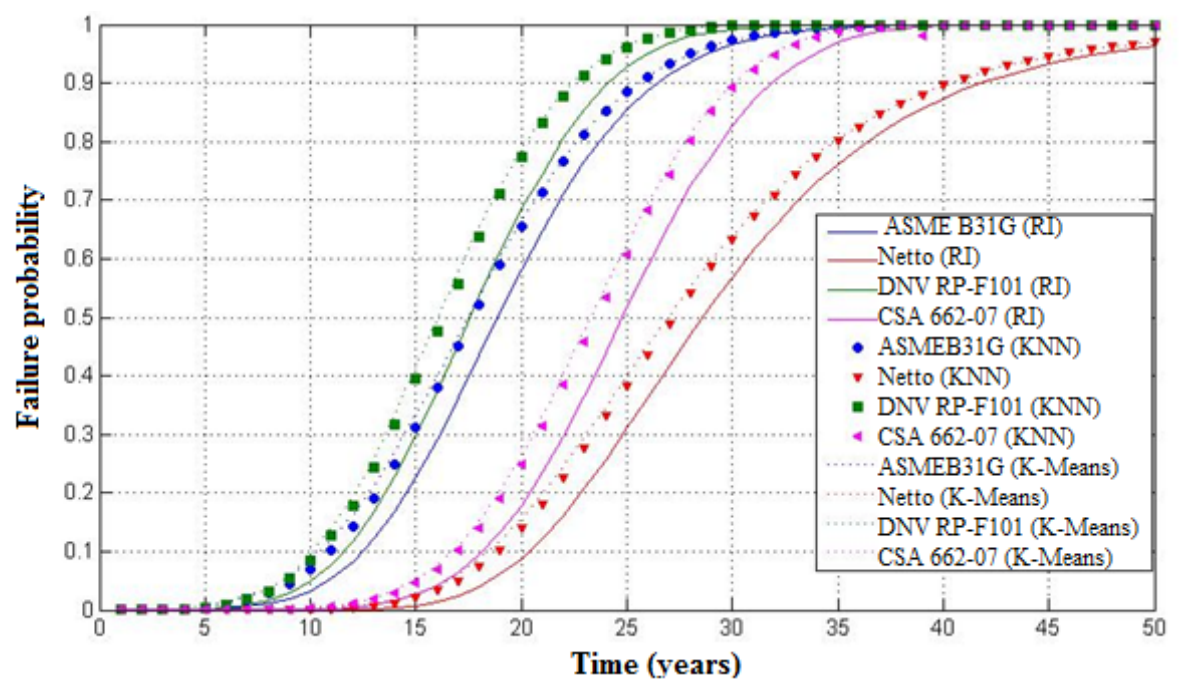

Figure 7. Failure probability results with the reliability index including groupings

It is worth to be mentioned that the failure probability of the grouping defects was calculated using the equivalent dimension (according to Figure 5), but those results correspond with the width and length of the new grouped defects. For their depth, it was used the maximum depth from the set of individual defects. Figure 7 shows that there is not a significant difference between the failure probability for the individual and grouped defects for a time shorter than 15 
years and greater than 35 years, but in the period between 15-35 years present an increase of $10 \%$ between the individual and grouped defects. This is coherent because the grouped defects by the ASMEB31G criterion only represents the $13 \%$ of all the defects reported in the ILI runs.

\subsection{Remaining life analysis}

It should be mentioned that the pipeline safety is not necessary related to their operating time, for example, only the $15 \%$ of the reported events in PHMSA during the period 2002-2009 were associated to that parameter. However, according to Kiefner (2012) [56] this factor may be the driving force for occurring accidents due to other hazards such as external corrosion or landslides. Therefore, it can be said that this approximation is useful to support decision making associated with the needed time between inspections or maintenances in order to extent their lifetime.

It was used the approximation from the standard API 579-1/ASME FFS-1 to determine the remaining life of the case of study. It was assumed that the pipeline has $85 \%$ of weld efficiency (E) and an allowable stress (S) of $72 \%$ of the yield stress, although an $80 \%$ could be used as is stated in [57].

A Monte Carlo simulation was developed to determine the remaining life of each corrosion defect in the ILI runs, using the probabilistic growth corrosion model explained above. From the results, the maximum, minimum, and average pipeline remaining life were calculated for each year simulated of all corrosion defects (Figure 8). In the results obtained, it can be noted that there exists corrosion defects that should be treated in the next five years, and that the pipeline would have a maximum remaining life of 50 years, which is consistent with the results obtained in Figure 4 and Figure 6.

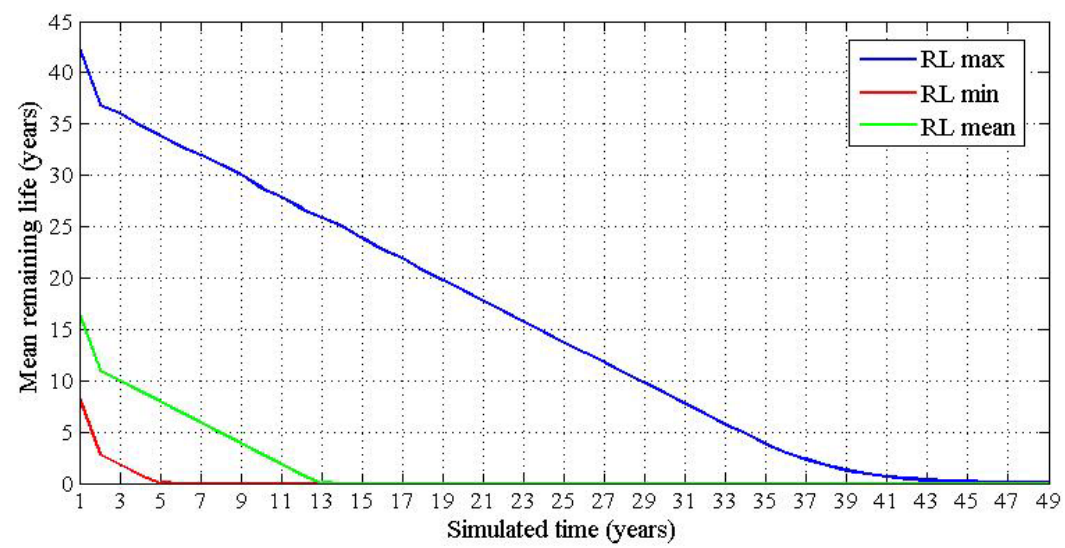

Figure 8. Maximum, minimum and mean remaining life

The remaining life results provide a perspective of the system status, projected over time. However, the API 579-1/ASME FFS-1 corresponds to a deterministic approximation even it is well known all the uncertainty associated in their evaluation. Consequently, it was developed two probabilistic approximations to determine the remaining life of the system (Figure 9). In the first place, it was used the numerator of [Eq. 5] as a limit state function, i.e. the difference between the minimum wall thickness and the average wall thickness in the last inspection. In second place, the results obtained from the maximum remaining life analysis were used to 
determine an empirical probability that the pipeline had a positive remaining life, in a given time t.

Figure 9 shows that the first approximation (Monte Carlo) has a 30\% probability of having a remaining life of 40 years (since the elapsed time of the ILI inspection), while the second approximation has a probability of $70 \%$ for the same year. Besides it could be noted that the system would have a remaining life greater than 30 years with a probability near of $100 \%$. The difference between the results obtained in both approximation, suggests that the API 5791/ASME FFS-1 is a conservative approximation to assess the remaining life of a pipeline, like it was exposed by Jaske [43]. Therefore, other approximations should be used to address this analysis. Deterioration process should take into account, principally random progressive deterioration which it is usually a slow continuous time-dependent phenomenon, which is caused, for instance, by chloride ingress, corrosion, or fatigue [44].

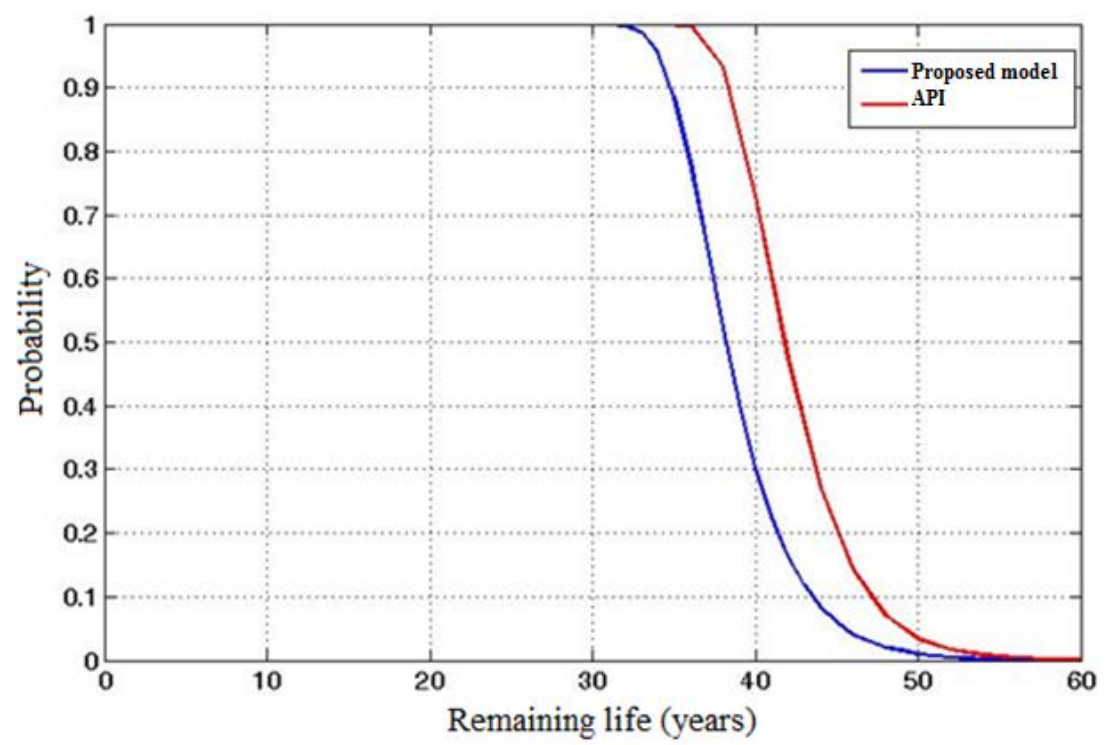

\section{Conclusions}

Figure 9. Remaining life probability

Based on the work done, it can be concluded that pattern recognition techniques and reliability concepts could be used to support decision making in oil pipelines. In the case of pattern recognition, supervised and unsupervised techniques were used to assess grouping corrosion defects. While the reliability concepts, were used to calculate an approach of the failure probability of the system.

It was implemented the k-nearest neighbors technique for a supervised learning and K-Mean for the unsupervised case. It was also evaluated two more supervised techniques (Fisher linear discriminant and Support Vector Machines) obtaining a mean squared error greater than the corresponding to k-nearest neighbors with 4 neighbors and an inverse kernel (parameters obtained by a Cross-Validation test).

Reliability concepts and Monte Carlo simulation were implemented to determine an approximation of the failure probability, obtaining similar results in both cases with the 
difference that the computational time for the reliability index case was substantially shorter in comparison to a conventional method as Monte Carlo.

The results obtained in the failure probability in the grouping and the individual defects assessment did not present a significant difference for a time shorter than 15 years and greater than 35 years, but in the period between 15-35 years it present an increase of 10\% between the individual and grouped defects.

The conventional models to assess the corrosion defects (the ASMEB31G and DNV RP-F101) correspond to conservative assessments in comparison to other models such as the Netto and CSA 662-07. Furthermore, one of these models should be used taking into account a grouping criterion such as the one from ASMEB31G, in order to not underestimate the failure probability or the remaining life of the pipeline.

\section{References}

[1] D. Cronin, "Assessment of corrosion defects in pipelines," National Library of Canada, Ottawa, 2000.

[2] Pipeline101, 2013. [Online]. Available: http://www.pipeline101.com/why-do-we-needpipelines/other-means-of-transport.

[3] US Dot PHMSA, "Data \& Statistics," 2015. [Online]. Available: http://www.phmsa.dot.gov/pipeline/library/data-stats. [Accessed February 2015].

[4] CONCAWE, "Performance of European cross-country oil pipelines. Statistical summary of reported spillages in 2012 and since 1971," December 2013. [Online]. Available: https://www.concawe.eu/DocShareNoFrame/docs/2/PAPHOGJALOBEBDLFDAPHIHFFVEVC W69YP3PDWK9DWDPW/CEnet/docs/DLS/Rpt_13-12-2014-01028-01-E.pdf. [Accessed February 2015].

[5] H. A. Kishawy and H. A. Gabbar, "Review of pipeline integrity management practices," International Journal of Pressure Vessels and Piping, no. 87, pp. 373-380, 2010.

[6] B. Eiber, Noviembre 2003. [Online]. Available: http://www.mrsc.org/artdocmisc/eiberoverview.pdf.

[7] A. Barbian and M. Beller, "In-Line Inspection of High Pressure Transmission Pipelines: State-ofthe-Art and Future Trends," in 18th World Conference on Nondestructive Testing, Durban, South Africa, 2012.

[8] NACE International, "NACE SP0169. Control of External Corrosion on Underground or Submerged Metallic Piping Systems," Houston, 2007.

[9] American Petroleum Institute, "Managing System Integrity forHazardous Liquid Pipelines," Washington,, 2013.

[10 American Petroleum Institute, "API 579-1/ASME FFS-1," Washington, 2007. ]

[11 American Society of Mechanical Engineers, "ASMEB31G: Manual for determining the remaining ] strength of corroded pipelines.," 2009.

[12 DNV, "Recommended practice DNV-RP-F101. Corrode Pipelines," Høvik, 2010. 
[13 A. Teixeria, C. Guedes Soares, T. Netto and S. Estefen, "Reliability of pipelines with corrosion ] defects," International Journal of Pressure Vessels and Piping, no. 85, pp. 228-237, 2008.

[14 A. Cosham and P. Hopkins, "THE ASSESSMENT OF CORROSION IN PIPELINES -

] GUIDANCE IN THE PIPELINE DEFECT ASSESSMENT MANUAL (PDAM)," in International Colloquium 'Reliability of High Pressure Steel Pipelines', Prague, Czech Republic, 2003.

[15 Kiefner \& Associates, Inc., "VALIDITY OF STANDARD DEFECT ASSESSMENT METHODS FOR THE ALLIANCE PIPELINE OPERATING AT 80\% OF SMYS," PHMSA, 2006.

[16 I. Barradas, L. E. Garza, R. Morales-Menendez and A. Vargas-Martínez, "Leaks Detection in a ] Pipeline Using Artificial Neural Networks," in CIARP, Guadalajara, México, 2009.

[17 N. A. Akram, D. Isa, R. Rajkumar and L. H. Lee, "Active incremental Support Vector Machine

] for oil and gas pipeline defects prediction system using long range ultrasonic transducers.," Ultrasonics, no. 54, pp. 1534-1544, 2014.

[18 Z. Qu, H. Feng, Z. Zeng, J. Zhuge and S. Jin, "A SVM-based pipeline leakage detection and pre] warning system," Measurement, no. 43, pp. 513-519, 2010.

[19 S. V. Bharath Kumar and S. Ramaswamy, "A texture analysis approach for automatic flaw ] detection in pipeline," in International Conference on Signal Processing \& Communications, 2004.

[20 V. Lacasse, J. Hay and R. Hay, "Pattern recognition of ultrasonic signals for detection of wall ] thinning," Signal Processing and Pattern Recognition in Nondestructive Evaluation of Materials, vol. 44, pp. 189-198, 1988.

[21 A. Barbian and M. Beller, "In-Line Inspection of High Pressure Transmission Pipelines: State-of] the-Art and Future Trends," in 18th World Conference on Nondestructive Testing, Durban, South Africa, 2012.

[22 Rosen, "Particular corrosion assessment methods," in Underground pipeline corrosion. Detection, ] analysis and prevention., Woodhead Publishing, 2014, pp. 73-76.

[23 V. Babbar, J. Bryne and L. Clapham, "Mechanical damage detection using magnetic flux leakage ] tools: modeling the effect of dent geometry and stresses," NDT\&E International, no. 38, pp. 471477, 2005.

[24 K. Reber and M. Beller, 2003. [Online]. Available: http://ppsa-online.com/papers/2003-2-

] Reber.pdf.

[25 A. Barbian, M. Beller, N. Thielager and H. Willems, "A New In-Line Inspection Tool For The

] Quantitative Wall Thickness Measurement Of Gas Pipelines: First Results," in 4th Pipeline Technology Conference, Hannover, 2009.

[26 R. Nyoborg, "Overview of CO2 Corrosion Models for Wells and Pipelines," Denver, 2002. ]

[27 S. Hasan, F. Khan and S. Kenny, "Probability assessment of burst limit state due to internal ] corrosion," International Journal of Pressure Vessels and Piping, no. 89, pp. 45-58, 2012.

[28 A. Amirat, A. Mohamed-Chateauneuf and K. Chaoui, "Reliability assessment of underground ] pipelines under the combined effect of active corrosion and residual stress," Pressure vessels and piping, no. 83, pp. 107-117, 2006.

[29 Y. Dodge, The Concise Encyclopedia of Statistics, New York: Springer, 2010, pp. 12-15. ] 
[30 B. J. Leira, "Structural Limit States and Reliability Measures," Trondheim, Springer, 2013, pp. 2] 12.

[31 G. Antaki, "Internal pressure," in Piping and pipeline engineering. Design, construction,

] mantenance, integrity and Repair, Aike, South Carolina, Marcel Dekker, 2005, pp. 84-121.

[32 CSA Z662-07, "Limit state equation for burst of large leaks and rupture for corrosion defect," ] 2007.

[33 T. Netto, U. Ferraz and S. Estefan, "The effect of corrosion defect on the burst presure of the ] pipeline," Journal of constructional steel research, vol. 61, no. 8, p. 1185-1204, 2005.

[34 R. Silva, J. Guerreiro and A. Loula, "A study of pipe interacting corrosion defects using the FEM

] and neural networks," Advances in Engineering Software, no. 38, pp. 868-875, 2007.

[35 V. Chauhan and W. Sloterdijk, "ADVANCES IN INTERACTION RULES FOR CORROSION

] DEFECTS IN PIPELINES," in International Gas Research Conference, IGRC, Vancouver , 2004.

[36 Pipeline Operators Forum, "Specifications and requirements for intelligent pig inspection of

] pipelines," 2008.

[37 S. Theodoridis and K. Koutroumbas, "Section 1.3: SUPERVISED VERSUS UNSUPERVISED

] PATTERN RECOGNITION," in Pattern Recognition, Greece, Elsevier Academic Press, 2003, pp. 6-8.

[38 M. J. BAXTER, "A REVIEW OF SUPERVISED AND UNSUPERVISED PATTERN

] RECOGNITION IN ARCHAEOMETRY," Archaeometry, vol. 48, no. 4, pp. 671-694, 2006.

[39 M. Sánchez-Silva, Introducción a la confiabilidad y evaluación de riesgo, Bogotá: Universidad de ] los Andes, 2010.

[40 B. M. Ayyub and R. H. McCuen, Probability, Statistics, and Reliability for Engineers and

] Scientists, Third ed., Boca Raton: CRC Press, 2011.

[41 Y.-G. Zhao and T. Ono, "A general procedure for ®rst/second-order reliability method

] (FORM/SORM)," Structural Safety, no. 21, pp. 95-112, 1999.

[42 V. Chauhan and T. Swankie, "Project \#153M Guidance for Assessing the Remaining Strength of

] Corroded Pipelines," Mechanicsburg, PA, 2010.

[43 C. E. Jaske, "Process Equipment Fitness-for-Service Assessments Using API RP 579," in Process

] \& Power Plant Reliability Conference, Houston, TX, 2001.

[44 M. Sánchez-Silva, G.-A. Klutke and D. V. Rosowsky, "Life-cycle performance of structures

] subject to multiple deterioration mechanisms," Structural Safety, no. 33, pp. 206-217, 2011.

[45 ROSEN, "Magnetic Flux Leakage," ROSEN, 2014. [Online]. Available: http://www.rosen-

] group.com/global/solutions/solution-scout.html?tag_technologies=magnetic-flux-leakage.

[46 Rosen, 2013. [Online]. Available: http://www.rosen-

] group.com/global/solutions/services/service/rocorr-mfl-c.html.

[47 H. Qin, "Probabilistic Modeling and Bayesian Inference of Metal-Loss Corrosion with

] Application in Reliability Analysis for Energy Pipelines," London (Ontario), 2014.

[48 T. ISOGAI, Y. KATANO and K. MIYATA, "Models and Inference for Corrosion Pit Depth

] Data," Extremes, vol. 7, no. 3, pp. 253-270, 2004.

[49 W. Zhou, H. Hong and S. Zhang, "Impact of dependent stochastic defect growth on system

] reliability of corroding pipelines," International Journal of Pressure Vessels and Piping, Vols. 9697, pp. 68-77, 2012. 
[50 Z. Guoguang and L. Jing, "Finite Element Modelling of Circumferential Magnetic Flux Leakage

] Inspection in Pipeline," in International Conference on Intelligent Computation Technology and Automation, Changsha, China, 2010.

[51 K. Dzioyev, K. Basiyev, G. Khabalov and E. Dzarukayev, "Stress corrosion processes in the metal ] and welded joints in gas pipelines," Welding International, vol. 28, no. 9, pp. 717-721, 2014.

[52 R. O. Duda, P. E. Hart and D. G. Storck, "3.8.2 Fisher Linear Discriminant," in Pattern

] Classification, New York, Wiley, 2001, pp. 117-121.

[53 G. A. BETANCOURT, "LAS MÁQUINAS DE SOPORTE VECTORIAL (SVMs)," Scientia et ] Technica, vol. 27, pp. 67-72, 2005.

[54 J. KIM, B.-S. KIM and S. SAVARESE, "Comparing Image Classification Methods: K-Nearest] Neighbor and Support-Vector-Machines," in Applied Mathematics in Electrical and Computer Engineering, Cambridge, USA, 2010.

[55 J. Hartigan and M. Wong, "Algorithm AS 136: A k-means clustering algorithm," Applied ] Statistics, vol. 28, no. 1, pp. 100-108, 1979.

[56 J. F. KIEFNER and M. J. ROSENFELD, "The Role of Pipeline Age in Pipeline Safety," ] Worthington,Ohio, 2012.

[57 Z. Xinwei, Z. Guangli, L. Jinheng and Z. Hua, "Impact of Improving Design Factor over 0.72 on ] the Safety and Reliability of Gas Pipelines and Feasibility Justification," CHINESE JOURNAL OF MECHANICAL ENGINEERING, vol. 25, no. 1, pp. 166-172, 2012. 